\title{
Assessment of hypertension management in primary health care settings in Kinshasa, Democratic Republic of Congo
}

\author{
Aimée M. Lulebo ${ }^{1,3^{*}}$, Mala A. Mapatano ${ }^{1}$, Patrick K. Kayembe ${ }^{1}$, Eric M. Mafuta' ${ }^{1}$ Paulin B. Mutombo ${ }^{1}$ \\ and Yves Coppieters ${ }^{2}$
}

\begin{abstract}
Background: Hypertension-related complications have become more diagnosed at secondary and tertiary care levels, in the Democratic Republic of the Congo (DRC), probably indicative of poor management of hypertensive patients at primary health care level. This study aimed to assess the management of hypertension in primary health care settings by using guidelines of the International Forum for Prevention and Control of HTN in Africa (IFHA).

Methods: A multi-center cross-sectional study was carried out in primary health care settings. A total of 102 nurses were surveyed using a structured interview. Mean and proportion comparisons were performed using the $t$ Student test and the Chi-square test respectively. The Kinshasa Primary Health Care network facilities were compared with non-Kinshasa Primary Health Care network facilities.

Results: From the 102 nurses surveyed; $52.9 \%$ were female with a mean age of 41.1 , (SD $=10)$ years, merely $9.5 \%$ benefited from in-job training on cardiovascular diseases or their risk factors, and $51.7 \%$ had guidelines on the management of hypertension. Less than a quarter of the nurses knew the cut-off values of hypertension, diabetes and obesity. Merely $14.7 \%$ knew the therapeutic goals for uncomplicated hypertension. Several of the indicators for immediate referral recommended by IFHA were unmentioned. The content of patient education was lacking, avoiding stress being the best advice provided to hypertensive patients. The antihypertensive most used were unlikely to be recommended by the IFHA.

Conclusions: This study showed a considerable gap of knowledge and practices in the management of hypertensive patients at primary health care facilities in Kinshasa pertaining to the IFHA guidelines. We think that task-shifting for management of hypertension is feasible if appropriate guidelines are provided and nurses trained.
\end{abstract}

Keywords: Hypertension, Management, Primary health care and DRC

\section{Background}

Africa is actually experiencing one of the most rapid epidemiological transitions characterized by a double disease burden with a mix of high incidence of infectious diseases and a growing prevalence of non-communicable diseases NCDs [1, 2]. Moreover $80 \%$ of the NCDs induced deaths occur in the low and middle income countries [3]. Hypertension is among the commoner NCDs.

\footnotetext{
* Correspondence: aimelulebo@yahoo.fr

'Kinshasa School of Public Health, Kinshasa, Democratic Republic of Congo

${ }^{3}$ Department of Epidemiology and Bio-statistics, Kinshasa School of Public

Health, University of Kinshasa, P.O. Box 11850, Kinshasa, Democratic Republic of Congo

Full list of author information is available at the end of the article
}

In Sub-Saharan Africa (SSA), the prevalence of hypertension varies from 6 to 48 \% [4]. In the Democratic Republic of Congo (DRC), the prevalence of hypertension has increased significantly from $14.2 \%$ in urban areas and $9.9 \%$ in rural areas in 1987 to $26.7 \%$ in $2005[5,6]$. Hypertension is a major cardiovascular risk factor (CVRF); it increases cardiovascular morbidity and mortality [7].

Health System (HS) related factors have a significant impact on the control of blood pressure control $[8,9]$. HS in African countries is essentially oriented to managing infectious diseases. Therefore, health professionals are unprepared to deal with NCDs, given the 
environment with its limited resources [10, 11]. Thus, cost-effective approaches are needed to lift health systems-level barriers for the management of NCDs in low and middle income countries (LMICs). The taskshifting strategy defined as the rational distribution of primary health care duties from physician to nonphysician health care providers is one of these approaches $[12,13]$. Previous studies carried out in LMICs have reported the effectiveness of this strategy in the management of HTN $[14,15]$.

Task-shifting is also considered in the Health policy of the DRC which is based on Primary Health Care (PHC). A Health Center $(\mathrm{HC})$ is run by a nurse. This represents the first level of care, the first-contact setting between patients and healthcare systems. Screening and management of NCDs such as hypertension and diabetes are included in the essential health activities package of HCs [16]. Patient management at the HC should comply with the Ministry of Health's guidelines. These guidelines, however, do not provide a clear indication on the management of HTN [17]. HCs have to refer patients to the General Referral Hospital (GRH) [16].

Actually, the referral health care facilities register more and more patients with HTN-related complications including stroke and chronic kidney disease (CKD) [18-21]. The Vitaraa study conducted in Southern Kivu (DRC), found that $86.4 \%$ of hypertensive patients were uncontrolled [22]. This shows the poor control of HTN in the country.

In 2003, the International Forum for Prevention and Control of HTN in Africa (IFHA) developed the guidelines for the management of hypertension in SSA countries [23]. These guidelines were adapted from the 2002 WHO Cardiovascular Risk Management Package in lowmedium Resource Settings. The IFHA guidelines use the global approach in the management of HTN, which aims to reduce the absolute risk by the management of multiple individual risk factors [24]. These recommendations emphasize the treatment of HTN, with particular attention to cost-effectiveness and affordability in SSA countries [23].

This study aimed to assess the management of Hypertension adhering to the IFHA guidelines in the primary health care facilities.

\section{Methods}

\section{Study design and population}

A multi-center, cross-sectional study was carried in Kinshasa, the capital city of the Democratic Republic of Congo (DRC) in July 2013. A total of 36 HCs were selected using a multiple stage sampling and a total of 102 nurses were surveyed. During the first stage, 12 Health Zones (HZ) were selected out of the $35 \mathrm{HZ}$ situated in the city using simple random sampling technique. During the second stage, in each selected $\mathrm{HZ}$, a list of $\mathrm{HCs}$ was generated and $\mathrm{HCs}$ were stratified according to their ownership (public, private and confessional). From each category, three HCs were randomly selected. From each selected $\mathrm{HC}$, three nurses involved in curative activities and present on the day of the survey, were interviewed.

The study protocol was approved by the Kinshasa School of Public Health Ethical Committee (ESP/CE/ 002/2012). All participants gave their verbal informed consent according to the Helsinki Declaration II. Participants' confidentiality was assured by not recording their identity or the name of health care facilities.

\section{Variables}

Data were collected during face-to-face interviews using a structured questionnaire. Variables were mainly drawn from the IFHA guidelines which have been adapted for the first level of care; with particular emphasis placed on clinical evaluation of risk factors adapted from the 2002 WHO Cardiovascular Risk Management Package in lowmedium Resource Settings scenario [25]. The IFHA guidelines have been summarized in terms of main skills expected from care-providers, as shown in Table 1.

\section{Statistical analysis}

Statistical analyses were performed using the statistical package for social sciences (SPSS) version 21.0. Categorical data were summarized as percentages and continuous data as mean and standard deviation (SD). Means and proportions comparisons were performed using respectively Student t-test, Chi-square test and the Fisherexact test when Chi-square could not be applied. The Kinshasa Primary Health Care network facilities (KPHC) and the non- KPHC network facilities were compared. The KPHC network facilities comprise a constellation of confessional health centers organized around referral hospitals. The KPHC network facilities have worked using an integrated approach in order to improve diabetes and hypertension care as previously described [26]. The non-KPHC network facilities are the other healthcare facilities which do not belong to this network.

\section{Results \\ Facilities identification and sample characteristics}

We interviewed 102 of 108 nurses (response rate: 94.4 \%). As summarized in Table 2, the majority of surveyed health facilities did not belong to the KPHC network $(78.0 \%)$. More than half of the nurses were female (52.9\%). Nurses from the KPHC network were older $(44.9 \pm 9.3$ years vs. $40.0 \pm 10.0$ years $)(p=0.043)$ and had a lower level of qualification (72.7 \% vs. $36.2 \%)(p=$ 0.002) than those working in the non-KPHC network. In terms of responsibility in the facility, $71.6 \%$ were not the head nurses. 
Table 1 Summary of IFHA recommendations and variables

\begin{tabular}{lll}
\hline Skills expected & Recommendations & Variables resulted \\
\hline $\begin{array}{l}\text { Identify } \\
\text { cardiovascular } \\
\text { risk factors }\end{array}$ & $\begin{array}{l}\text { These cardiovascular risk factors must be explored: patient personal history } \\
\text { (CVD and diabetes) and family history of premature CVD, age, sex, smoking, } \\
\text { alcohol consumption, physical inactivity, obesity, diet poor in fruits and } \\
\text { vegetables, salt intake. }\end{array}$ & $\begin{array}{l}\text {-Knowledge of cardiovascular diseases } \\
\text {-Knowledge of cardiovascular risk factors } \\
\text {-Knowledge of cut-off values of cardiovascular risk } \\
\text { factors (HTN, diabetes and obesity) }\end{array}$ \\
$\begin{array}{l}\text { Assess } \\
\text { cardiovascular } \\
\text { risk level. }\end{array}$ & $\begin{array}{l}\text { Patients are stratified in four levels of cardiovascular risk: low, medium, high } \\
\text { and very high risk. Patients with high and very high cardiovascular risk must } \\
\text { be referred in the next level of care. }\end{array}$ & $\begin{array}{l}\text { Indication for immediate referrals } \\
\text { Perform patient } \\
\text { education }\end{array}$ \\
$\begin{array}{l}\text { Counseling on diet including excessive alcohol intake, physical activity and } \\
\text { Provide medical } \\
\text { treatment }\end{array}$ & Hydrochlorothiazide in low dosage. & Content of patients' education \\
\hline
\end{tabular}

\section{Job training and existence/availability of guidelines}

Table 2 also summarizes the existence of job training and guidelines. Although, 84 nurses declared they had already received in-job training, only a negligible proportion of them (9.5\%) have received in-job training on cardiovascular diseases or on their risk factors (hypertension, diabetes...). Furthermore, the proportion of those who had received injob training on cardiovascular diseases and on related risk factors was significantly lower in the non-KPHC network facilities compared to the KPHC network facilities (3.1\%

Table 2 Sample characteristics and job training

\begin{tabular}{|c|c|c|c|c|}
\hline \multirow[t]{2}{*}{ Variables } & Overall n (\%) & KPHC Network facilities n (\%) & Non KPHC Network facilities n (\%) & \multirow[t]{2}{*}{$p$} \\
\hline & $n=102$ & $n=22$ & $n=80$ & \\
\hline \multicolumn{5}{|l|}{ Sex of respondents } \\
\hline Male & $48(47.1)$ & $8(36.4)$ & $40(50.0)$ & \multirow[t]{3}{*}{0.256} \\
\hline Female & $54(52.9)$ & $14(63.6)$ & $40(50.0)$ & \\
\hline \multirow[t]{2}{*}{ Age } & Mean \pm SD & Mean \pm SD & Mean \pm SD & \\
\hline & $41.1 \pm 10.0$ & $44.9 \pm 9.3$ & $40.0 \pm 10.0$ & $0.043^{*}$ \\
\hline Function & n (102) & $(n=22)$ & $(n=80)$ & \multirow[t]{3}{*}{0.892} \\
\hline Head nurse & $29(28.4)$ & $6(27.3)$ & $23(28.8)$ & \\
\hline Others nurses & $73(71.6)$ & $16(72.7)$ & $57(71.2)$ & \\
\hline \multicolumn{5}{|l|}{ Qualification } \\
\hline High level & $57(55.9)$ & $6(27.3)$ & $51(63.8)$ & \multirow[t]{2}{*}{$0,002^{*}$} \\
\hline Low level & $45(44.1)$ & $16(72.7)$ & $29(36.2)$ & \\
\hline \multicolumn{5}{|l|}{ Job training } \\
\hline Yes & $84(82.4)$ & $19(86.4)$ & $65(81.3)$ & \multirow[t]{2}{*}{0,757} \\
\hline No & $18(17.6)$ & $3(13.6)$ & $15(18.7)$ & \\
\hline \multicolumn{5}{|l|}{ Period of last job training } \\
\hline 1 year or less & $61(72.6)$ & $14(73.7)$ & $47(72.3)$ & \multirow[t]{2}{*}{0,906} \\
\hline More than 1 year & $23(27.4)$ & $5(26.3)$ & $18(27.7)$ & \\
\hline Job training on CVD or CVRF & $(n=84)$ & & & \\
\hline Yes & $8(9.5)$ & $6(31.6)$ & $2(3.1)$ & \multirow[t]{2}{*}{$0.001^{*}$} \\
\hline No & $76(90.5)$ & $13(68.4)$ & $63(96.9)$ & \\
\hline Existence of guidelines & $(n=102)$ & & & \\
\hline Yes & $58(56.9)$ & $18(81.8)$ & $40(50.0)$ & \multirow[t]{2}{*}{$0.008^{*}$} \\
\hline No & $44(43.1)$ & $4(18.2)$ & $40(50.0)$ & \\
\hline Existence of guidelines for management of hypertension & $(n=58)$ & & & \\
\hline Yes & $30(51.7)$ & $12(66.7)$ & $18(45.0)$ & \multirow[t]{2}{*}{0.127} \\
\hline No & $28(48.3)$ & $6(33.3)$ & $22(55.5)$ & \\
\hline
\end{tabular}

* means statistically significant 
vs. $31.6 \%)(p=0.001)$. More of KPHC network facilities were in possession of guidelines for the management of patients than the non-KPHC network facilities $(81.8 \%$ vs. $50.0 \%)(p=0.008)$. However, no statistical difference was observed regarding the presence/availability of guidelines for the management of hypertension between both groups $(66.7 \%$ vs. $45.0 \%)(p=0.127)$.

\section{Assessment of health-care providers' knowledge}

Table 3 presents an assessment of health-care providers' knowledge. More than $50 \%$ of health providers in both groups were able to mention at least one CVD. Nurses from the KPHC network were more capable than those from non KPHC network in naming at least three cardiovascular risk factors $(68.2 \%$ vs. $30.0 \%)(p=0.001)$. The most common cardiovascular risk factor mentioned was stress $(60.0 \%)$. The cut-off values of BP for HTN $(\geq 140 / 90 \mathrm{mmHg}$ ) was reported by less than half of them and this proportion was lower among nurses of nonKPHC network compared to those of KPHC network $(17.5 \%$ vs. $40.9 \%)(p=0.040)$. The cut-off value of diabetes $(\geq 126 \mathrm{mg} / \mathrm{dl})$ was mentioned by less than one fifth of nurses, but this proportion was lower among nurses from non KPHC network (1.3 \% vs. $13.6 \%)(p=0.031)$.

Table 3 Assessment of health care providers' knowledge

\begin{tabular}{|c|c|c|c|c|}
\hline \multirow[t]{2}{*}{ Variables } & Overall n (\%) & KPHC Network facilities n (\%) & Non KPHC Network n (\%) & \multirow[t]{2}{*}{$p$} \\
\hline & $n=102$ & $n=22$ & $n=80$ & \\
\hline \multicolumn{5}{|l|}{ CVD knowledge } \\
\hline Have cited at least one & $59(57.8)$ & $14(63.6)$ & $45(56.3)$ & \multirow[t]{2}{*}{0.534} \\
\hline Did not cite any & $43(42.2)$ & $8(36.4)$ & $35(43.7)$ & \\
\hline \multicolumn{5}{|l|}{ CVRF knowledge } \\
\hline Have cited 3 or more & $39(38.2)$ & $15(68.2)$ & 24(30.0) & \multirow[t]{2}{*}{$0.001^{*}$} \\
\hline Have cited less than 3 & $63(61.8)$ & $7(31.8)$ & $56(70.0)$ & \\
\hline \multicolumn{5}{|l|}{ CVRF mentioned } \\
\hline Hypertension & $33(32.4)$ & $8(36.4)$ & $25(31.3)$ & 0.650 \\
\hline Diabetes & $16(15.7)$ & $8(36.4)$ & $8(10.0)$ & $0.006^{*}$ \\
\hline Obesity & $25(24.5)$ & $9(40.9)$ & $16(20.0)$ & $0.043^{*}$ \\
\hline Tobacco use & $20(19.6)$ & $4(18.2)$ & $16(20.0)$ & 1.000 \\
\hline Alcohol consumption & $23(22.5)$ & $6(27.3)$ & $17(21.3)$ & 0.571 \\
\hline Diet rich in fat & $16(15.7)$ & $6(27.3)$ & $10(12.5)$ & 0.106 \\
\hline Ageing & $10(9.8)$ & $4(18.2)$ & $6(7.5)$ & 0.216 \\
\hline Stress & $53(60.0)$ & $8(36.4)$ & $45(56.3)$ & 0.098 \\
\hline Salt intake & 19 (18.6) & $5(22.7)$ & $14(17.5)$ & 0.550 \\
\hline \multicolumn{5}{|c|}{ Cut-off values of Hypertension } \\
\hline Know & $23(22.5)$ & $9(40.9)$ & $14(17.5)$ & \multirow[t]{2}{*}{$0.040^{*}$} \\
\hline Do not know & $79(77.5)$ & $13(59.1)$ & $66(82.5)$ & \\
\hline \multicolumn{5}{|l|}{ Cut-off value of diabetes } \\
\hline Know & $4(3.9)$ & $3(13.6)$ & $1(1.3)$ & \multirow[t]{2}{*}{$0.031^{*}$} \\
\hline Do not know & $98(96.1)$ & $19(86.4)$ & $79(98.7)$ & \\
\hline \multicolumn{5}{|c|}{ Cut-off values of BMI for obesity } \\
\hline Know & $3(2.9)$ & $1(4.5)$ & $2(2.5)$ & \multirow[t]{2}{*}{0.521} \\
\hline Do not know & $99(97.1)$ & $21(95.5)$ & $78(97.5)$ & \\
\hline \multicolumn{5}{|c|}{ Therapeutic goals for uncomplicated hypertension } \\
\hline Know & $15(14.7)$ & $2(9.1)$ & $13(16.3)$ & \multirow[t]{2}{*}{0.514} \\
\hline Do not know & $87(85.3)$ & $20(90.9)$ & $67(83.7)$ & \\
\hline \multicolumn{5}{|c|}{ Therapeutic goals for complicated hypertension } \\
\hline Know & $3(2.9)$ & $0(0.0)$ & $3(3.8)$ & \multirow[t]{2}{*}{1.000} \\
\hline Do not know & $99(97.1)$ & $22(100.0)$ & $77(96.2)$ & \\
\hline
\end{tabular}

* means statistically significant 
The cut-off values of obesity's index (body mass index (BMI) and waist circumference) were almost unknown by nurses in both groups. A very low proportion of nurses (14.7 \%) knew that Systolic Blood Pressure (SBP) $<140 \mathrm{mmHg}$ and Diastolic Blood Pressure (DBP) $<90 \mathrm{mmHg}$ are the therapeutic goals for uncomplicated hypertension. A similar result was found for the therapeutic goals for complicated hypertension (SBP $<130 \mathrm{mmHg}$ and DBP $<80 \mathrm{mmHg}$ ).

\section{Indication for immediate referral, contents of hypertensive patient education and the most used antihypertensive medication}

Table 4 shows that $83.3 \%$ of nurses mentioned at least one indicator for immediate referral according to the IFHA recommendations. Hypertension grade 3, patients with signs of stroke and patients with coma were the most mentioned indications. Table 4 reported also on health providers' practices concerning hypertensive patient education and antihypertensive medication. Avoiding stress (66.7 \%) and salt (53.9 \%) were the most mentioned advices/recommendations provided by nurses during hypertensive patient education. The most prescribed antihypertensive drug was Alpha methyldopa, and diuretics, namely Furosemide and hydrochlorothiazide.

\section{Discussion}

This study shows a considerable gap in knowledge and practices among nurses in their management of hypertension according to the IFHA guidelines. Secondly, few health-care providers declared having used the guidelines for the management of HTN. Although, KPHC providers were more knowledgeable than those from non-KPHC facilities, their knowledge and practices were, however, sub-optimal according to the IFHA guidelines.

The lack of an adequately trained health workforce for the management of non-communicable diseases is described as a challenge for SSA countries [27, 28]. This is corroborated by our findings where it was reported that a low proportion of nurses have received in-job training on cardiovascular diseases or on their risk related factors while a majority of them have reported to have already received in-job training probably on infectious diseases.

In the global approach, the knowledge of cardiovascular risk factors is essential for patients' cardiovascular risk assessment but also for the patients' management which must be global. In this study, we found that a low proportion of nurses were knowledgeable on cardiovascular diseases and their risk related factors. Stress was the most cardiovascular risk related factor mentioned and its prevention the commonest advice provided to hypertensive patients; whereas the commoner cardiovascular risk factors such as tobacco consumption,

Table 4 Indication for immediate referral, contents of hypertensive patient education and the most used antihypertensive medication

\begin{tabular}{|c|c|c|c|c|}
\hline Variables & Overall n (\%) & KPHC Network facilities n (\%) & Non KPHC Network n (\%) & $P$ \\
\hline \multicolumn{5}{|c|}{ Indications for immediate referral according to the IFHA recommendations } \\
\hline Mentioned at least one indication & $85(83.3)$ & $19(86.4)$ & $66(82.5)$ & \multirow[t]{2}{*}{1.000} \\
\hline Mentioned none & $17(16.7)$ & $3(13.6)$ & $14(17.5)$ & \\
\hline \multicolumn{5}{|l|}{ Patient education content } \\
\hline Avoid stress & $68(66.7)$ & $11(50.0)$ & $57(71.3)$ & 0.061 \\
\hline Diet without salt / Low-salt diet & $55(53.9)$ & $13(59.1)$ & $42(52.5)$ & 0.583 \\
\hline Drink of plenty water & $13(12.7)$ & $3(13.6)$ & $10(12.5)$ & 1.00 \\
\hline Take a rest & $25(24.5)$ & $3(13.6)$ & $22(27.5)$ & 0.181 \\
\hline Avoid coffee & $11(10.8)$ & $3(13.6)$ & $8(10.0)$ & 0.699 \\
\hline Avoid alcohol & $16(15.7)$ & $2(9.1)$ & $14(17.5)$ & 0.512 \\
\hline Respect taking medications and follow-up visits & $23(22.5)$ & $9(40.9)$ & $14(17.5)$ & $0.040^{*}$ \\
\hline Avoid foods high in saturated fat & $13(12.7)$ & $1(4.5)$ & $12(15.0)$ & 0.289 \\
\hline Physical activity & 19 (18.6) & $7(31.8)$ & $12(15.0)$ & 0.118 \\
\hline \multicolumn{5}{|l|}{ The most antihypertensive used } \\
\hline Aldomet & $41(40.2)$ & $3(13.6)$ & $38(47.5)$ & \multirow[t]{5}{*}{$0.000^{*}$} \\
\hline Furosemide & $24(23.5)$ & $1(4.5)$ & $23(28.8)$ & \\
\hline Esidrex & $16(15.7)$ & $15(68.2)$ & $1(1.3)$ & \\
\hline Sub lingual adalat & $15(14.7)$ & $1(4.5)$ & $14(17.5)$ & \\
\hline Others & $7(6.9)$ & $2(9.1)$ & $4(5.0)$ & \\
\hline
\end{tabular}


unhealthy diet including excessive alcohol intake and physical inactivity were less mentioned. It is described that the control of these CVRFs has a favourable effect on blood pressure [29]. Counseling by health providers can have a significant impact in motivating and supporting patients' behavioural change; unfortunately very often health providers inappropriately counsel patients about their life style as also reported by previous studies [30, 31].

This study indicates that the index of obesity was unknown by almost all care-providers. Nevertheless, it is established that obesity is a predictor of mortality among hypertensive patients and that weight loss significantly decreases blood pressure [20,32]. It suggests that health providers do not place emphasis on evaluating clearly patients' nutritional status. This finding is corroborated by Mongati et al. who reported that none of the health workers interviewed in their study knew how to measure waist circumference [31]. The awareness of therapeutic goals is a major element for preventing clinical inertia among healthcare providers and their ignorance is a factor in the poor control of blood pressure. Clinical inertia is defined as the failure of health-care providers to initiate or to intensify therapy when therapeutic goals are not reached [33]. Mendis et al. found that a lower proportion of non physician health care workers (NPHWs) knew the goals of treatment for uncomplicated hypertension compared to physicians (39\% vs. $75 \%$ ) [34]. This study provides an even worse conclusion than Mendis et al.

According to the IFHA guidelines, patients with a high or very high cardiovascular risk should be referred to a higher health care level. Among patients with a high cardiovascular risk are included hypertensive patients with antecedents of diabetes, cardiovascular diseases, CKD; patients with hypertension grade 1 or 2 associated to 3 or more other cardiovascular risk factors and all patients with hypertension grade 3 [18]. Some of them, namely patients with HTN grades 3, patients with signs of stroke and patients in coma have been the most mentioned indications for immediate referral among the surveyed nurses. Subsequently, the management of this category of patients should not be realized at primary health level but at a General Referral Hospital or at the highest level of health care. This study shows that some patients with a high or very high cardiovascular risk are being managed at the $\mathrm{HC}$ level which provides only an essential package of care, insufficient for managing patients in this category. This could explain the frequency of hypertension-related complications registered at the high care level.

Furthermore, this study showed that Alpha methyldopa, Furosemide and Thiazides were the most administered antihypertensive drugs by nurses; this finding corresponds almost to that of Mendis et al. [34], whereas the IFHA guidelines indicate that the anti-hypertensive drugs with central action like Methyldopa should only be used for resistant hypertension [23]. Also, it is more expensive than hydrochlorothiazide [34]. On the other hand, Furosemide is also recommended according to the IFHA guidelines for selected indications including congestive heart failure, advanced renal disease or refractory hypertension [23] and not for all patients.

Despite the fact that nurses of KPHC network had lower qualifications than others, their knowledge and practices were better probably because these healthcare providers received in-job training and were in possession of guidelines with a global approach that recommends hydrochlorothiazide as the first line drug. The nonKPHC network facilities had their guidelines included in the guidelines of care at Health Centers produced by the DRC Ministry of Health. These guidelines, place the diagnosis of hypertension in the symptoms' context notably headache or coma and recommends Furosemide associated with diazepam as antihypertensive medication. The DRC Ministry of Health recommends to HCs to manage hypertension but it does not provide them with suitable resources. We think that the task-shifting for hypertension management is feasible in DRC if appropriate guidelines are produced and nurses trained like reported by previous studies $(14,15)$.

However, this study has some limitations. The first limitation is related to the setting and small sample size which makes findings unrepresentative of the country. There is also a limitation from data collection; nurses surveyed self-reported their practices which were not observed. To the best of our knowledge, this study is the first to have assessed the management of HTN at the primary level of care facilities including also facilities which do not belong to the KPHC Network. In addition, this study can be a starting point for improving the management of HTN in the DRC.

\section{Conclusion}

This study showed a considerable gap in knowledge and practices related to management of hypertensive patients at primary health care facilities in Kinshasa according to the IFHA guidelines. This situation was mainly due to the lack of in-job training and the non-optimal quality of therapeutic guidelines on the management of hypertension. These findings imply that the improvement of the healthcare service delivery for hypertension requires that healthcare providers be trained, and that appropriate therapeutic guidelines are designed.

\section{Availability of supporting data}

The data set supporting the results of this study is available in an additional file. 


\section{Abbreviations}

CKD: Chronic kidney disease; CVD: Cardiovascular diseases;

CVRF: Cardiovascular risk factor; DBP: Diastolic blood pressure; DRC: Democratic Republic of Congo; GRH: General Referral Hospital; HC: Health Center; HS: Health system; HTN: Hypertension; HZ: Health zones; IFHA: International forum for prevention and control of hypertension in Africa; KPHC: Kinshasa Primary Health Care; LMICs: Low and middle income countries; NCDs: Non-communicable diseases; NPHWs: Non physician health care workers; PHC: Primary Health Care; SBP: Systolic blood pressure; SD: Standard deviation; SSA: Sub-Saharan Africa; WHO: World Health Organization.

\section{Additional file}

Additional file 1: Dataset. This file contains data supporting the results of this study (http://dx.doi.org/10.5061/dryad.r7082).

\section{Competing interests}

No conflict.

\section{Authors' contributions}

$\mathrm{AL}$ designed the research, conducted field, analyzed data and wrote the paper. YC designed the research work and revised the manuscript. MM designed the research and revised the manuscript. PK revised the manuscript, EM wrote the paper. PM wrote the paper. AL had the primary responsibility for the final content. All authors read and approved the final manuscript.

\section{Acknowledgment}

We acknowledge all health care providers for their participation. We are thankful to the African Population Health Research Center (APHRC) and the United States Agency for International Development (USAID) for funding the thesis of Aimée Lulebo Mampasi. This work is a preliminary report of data collected for her thesis. Also we would like to thank Future Health Systems (FHS) for providing small grants to Kinshasa School of Public Health through Africa Hub, funded by the Department for International Development (DFID) for stationery paper. These findings sources are non-commercial.

\section{Author details}

${ }^{1}$ Kinshasa School of Public Health, Kinshasa, Democratic Republic of Congo. ${ }^{2} \mathrm{~S} c h o o l$ of Public Health, Université Libre de Bruxelles (ULB), Brussels, Belgium. ${ }^{3}$ Department of Epidemiology and Bio-statistics, Kinshasa School of Public Health, University of Kinshasa, P.O. Box 11850, Kinshasa, Democratic Republic of Congo.

\section{Received: 6 August 2015 Accepted: 11 December 2015}

\section{Published online: 24 December 2015}

\section{References}

1. Njelekela MA, Mpembeni R, Mligiliche NL, Spiegelman D, Hertzmark E, Liu $E$, et al. Gender related differences in the prevalence of cardiovascular disease risk factors and their correlated in urban Tanzania. BMC. 2009;17:9-30.

2. Yusuf S, Reddy S, Ônpuu S, Anand S. Global burden of cardiovascular diseases part l: general considerations, the Epidemiologic Transition, Risk Factors, and Impact of Urbanization. Circulation. 2001:104:2746-53.

3. WHO. Global Status Report on Non-communicable diseases 2010 http://www.Who.int/nmh/publications/ncd_report_full_en.pdf (accessed 13 April 2013)

4. Dalal S, Beunza JJ, Volmink J, Adebamowo C, Bajunirwe F, Njelekela M, et al. Non-communicable diseases in sub-Saharan Africa: what we know now. Int J Epidemiol. 2011:40:885-901.

5. M'Buyamba-Kabangu JR, Fagardr ST, Lijnen P, Amery A. Correlates of blood pressure in rural and urban Zaire. J Hypertens. 1987;5:371-5.

6. Longo MB, Ngoma VD, Nahimana D, Mupepe MD, Mbungu FS, Ekwanzala F, et al. Screen detection and the WHO STEPwise approach to the prevalence and risk factors of arterial hypertension in Kinshasa. Eur J Cardiovasc Prev Rehabil. 2008;15:503-8.
7. Connor M, Rheeder P, Bryer A, Meredith M, Beukes M, Dubb A, et al. The South African Stroke Risk in General Practice Study. S Afr Med J. 2005;95: 334-9.

8. Doroodchi H, Abdolrasulnia M, Foster JA, Foster E, Turakhia MP, Skelding KA, et al. Knowledge and attitudes of primary care physicians in the management of patients at risk for cardiovascular events. BMC Fam Pract. 2008;9:42.

9. Pellegrini F, Belfiglio M, De Bernadis G, Di Nardo B, Grienfield S, et al. Role of organizational factors in poor blood pressure control in patients with type 2 diabetes. Arch Intern Med. 2003;163:473-80.

10. Belue R, Okoror TA, Lwelunmor J, Taylor KD, Degboe AN, Agyemang C, et al. An overview of cardiovascular risk factor burden in sub-Saharan African countries: a socio-cultural perspective. Global Health. 2009;22: 5-10.

11. Mamo Y, Seid E, Adams S, Gardiner A, Parry E. A primary health care approach to the management of chronic diseases in Ethiopia: an example for other countries. Clin Med. 2007;7:228-31.

12. Alleyne G, Hancock C, Hughes P. Chronic and non-communicable diseases: a critical challenge for nurses globally. Int Nurs Rev. 2011;58:328-31.

13. Ogedegbe G, Gyamfi J, Plange-Rhule J, Surkis A, Rosenthal MD, Airhihenbuwa C, et al. Task Shifting interventions for cardiovascular risk reduction in low-income and middle-income countries: a systematic review of randomized controlled trials. BMJ Open. 2014;4:e005983. doi:10.1196/ bmjopen-2014-005983.

14. Mendis S, Johnston SC, Fan W, Oladapo O, Cameron A, Faramawi FM. Cardiovascular risk management and its impact on hypertension control in primary care in low -resource settings: a cluster randomized trial. Bull World Health Organ. 2010;88:412-9.

15. Adeyemo A, Tayo BO, Luke A, Ogedegbe O, Durazo-Arvizu R, Cooper RS The Nigerian-Antihypertensive Adherence Trial (NA-HAT): a communitybased randomized trial. J Hypertens. 2013;31(1):201-7.

16. Ministère de la Santé Publique/RD Congo. Normes de zones de santé 2ième éd. Kinshasa: Ministère de la Santé Publique/ RD Congo; 2010.

17. Ministère de la Santé Publique RD/Congo. Ordinogrammes des soins au Centre de Santé. Kinshasa: Projet d'appui à la réhabilitation du secteur de la santé; 2008.

18. Sumaili EK, Krzesinski JM, Cohen EP, Nseka NM. Epidemiologie de la maladie rénale chronique en Republique Démocratique du Congo : revue des études transversales de Kinshasa, la capitale. Nephrol Ther. 2010;6(4):232-9.

19. Sumaili KE, Nseka NM, Makulo JRR, Zinga CV, Longo AL, Mukendi SK, et al. Statut socioéconomique et protéinurie : résultats de campagne de dépistage des maladies des reins 2007 à Kinshasa. Ann Afr Med. 2009;2:3.

20. M'Buyamba KJR, Biswika RT, Thijs L, Tshimanga GM, Ngalula FM, Disashi T, et al. In-hospital mortality among black patients admitted for hypertensionrelated disorders in Mbuji Mayi, Congo. Am J Hypertens. 2009;22:643-8.

21. Kintoki F. Tendance séculaire des accidents vasculaires cérébraux, facteurs de risque non modifiables, saisons, El Nino et traitement. Mémoire de spécialisation. Université de Kinshasa. 2007.

22. Katchunga BP, Mbuyamba KJR, Masumbuka EB, Lemogoum D, Kashongwe MZ, Degaute JP et al. Hypertension in adult Congolese population in Southern Kivu: Results of the Vitaraa Study. Presse Médicale 2011. doi: 10.1016/jlpm 2010.10.036.

23. Lemogoum D, Seedat YK, Mabadeje AF, Mendis S, Bovet $P$, Onwubere B, et al. Recommendations for prevention, diagnosis and management of hypertension and cardiovascular risk factors in sub-Saharan Africa. J Hypertens. 2003;21:1993-2000.

24. National Vascular Disease Prevention Alliance. Guidelines for the management of absolute cardiovascular disease risk. The Royal Australian College of General Practitioners. 2012.

25. WHO. CVD-risk management package for low and medium-resource settings. Geneva: World Health Organization; 2002.

26. Kapongo YR, Lulebo MA, Mafuta ME, Mutombo BP, Dimbelolo MJC, Bieleli. Assessment of health service delivery capacities, health providers' knowledge and practices related to type 2 diabetes care in Kinshasa primary health care network facilities, Democratic Republic of Congo. BMC Health Serv Res. 2015;15:9.

27. Kengne AP, Sobngwi E, Fezeu L, Awah KP, Dongmo S, Mbanya JC. Settingup nurse-led pilot clinics for the management of non-communicable diseases at primary health care level in resource-limited settings of Africa. Pan Afr Med J. 2009;3:10. 
28. Anderson FG, Chu E. Expanding priorities - confronting chronic diseases in countries with low income. N Engl J Med. 2007;356:3.

29. Dagogo SJ, Egbuonu N, Edeoga C. Principles and practice of non pharmacological interventions to reduce cardiometabolic risk. Med Princ Pract. 2010;19:167-75.

30. Powell-Wiley MT, Ayers RC, Banks-Richard K, Berry DJ, Khera A, Lakoski GS, et al. Disparities in counseling for life style modification among obese adults: insights from the Dallas heart study. Obesity. 2012;20(4):849-55.

31. Mungati M, Manangazira P, Takundwa L, Gombe NT, Rusakaniko S, Tshimanga $\mathrm{M}$. Factors affecting diagnostics and management of hypertension in Mazowe District of Mashonaland Central Province in Zimbabwe: 2012. BMC Cardiovasc Disord. 2014;14:102.

32. Agence nationale d'accréditation et d'évaluation en santé. Méthodes d'évaluation du risque cardiovasculaire global. France: Agence nationale d'accréditation et d'évaluation en santé; 2004.

33. Lebeau JP, Cadwallader JS, Aubin-Auger I, Mercier A, Pasquet T, Rusch E, et al. The concept and definition of therapeutic inertia in hypertension in primary care : a qualitative systematic review. BMC Fam Pract. 2014;15:130.

34. Mendis S, Abegunde D, Oladapo O, Celletti Fand Nordet P. Barriers to management of cardiovascular risk in a low resource setting using hypertension as an entry point. J Hypertens. 2004;22:59-64.

\section{Submit your next manuscript to BioMed Central} and we will help you at every step:

- We accept pre-submission inquiries

- Our selector tool helps you to find the most relevant journal

- We provide round the clock customer support

- Convenient online submission

- Thorough peer review

- Inclusion in PubMed and all major indexing services

- Maximum visibility for your research

Submit your manuscript at www.biomedcentral.com/submit 